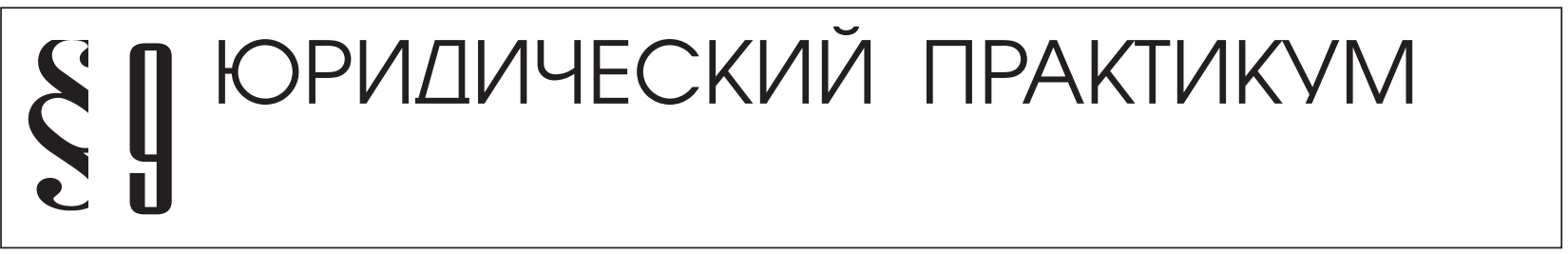

Козина Е.A.

\title{
К ВОПРОСУ О ПРИЧИНЕ ПРАВОВЫХ ПРОБЛЕМ НАСЛЕДОВАНИЯ ДОЛИ В УСТАВНОМ КАПИТАЛЕ ОБЩЕСТВА С ОГРАНИЧЕННОЙ ОТВЕТСТВЕННОСТЬЮ
}

\begin{abstract}
Аннотация: Предметом исследования является практика применения судами правовых норм, регулирующих переход доли в уставном капитале общества с ограниченной ответственностью в порядке наследования. Автор подробно рассматривает проблематику наследования доли в целях выявления ее причины, которую он видит не столько в нахождении рассматриваемых отношений на стыке регулирования двух (корпоративного и наследственного) подотраслей права, сколько в правовой природе доли в уставном капитале общества с ограниченной ответственностью. На основании детального анализа нормативной базы, судебных актов и теоретических исследований автор ставит под сомнение верность сложивщегося понимания сути данного объекта гражданских правоотнотений, которое не учитывает его комплексный характер. Метод сравнительного правоведения, комплексный анализ, системный подход, а также методы формальнологического толкования и правового моделирования. Автор рассматривает долю в уставном капитале общества в качестве сложного объекта, которому присущи признаки, вытекающие из понятия «комплекс»: множественность элементов (《прав из доли»), неделимость и единство этих элементов, обособленность данной совокупности прав от иного имущества участника общества. Исходя из презумпиии неделимости прав, формирующих долю в уставном капитале общества, автор делает вывод о том, что гражданско-правовой режим рассматриваемого объекта не должен допускать перехода к наследникам или иным третьим лицам части «прав из доли». В частности, автор предлагает исключить из законодательства нормы о возможности наследования доли, поскольку они искажают комплексную природу доли и создают предпосылки для приобретения наследниками имущественного права «из доли» (в частности, права требовать выплаты действительной стоимости доли) отдельно от корпоративных прав, которые могут не возникнуть у наследника при наличии ряда условий.
\end{abstract}

Ключевые слова: Наследование, общество, доля, уставный капитал, участник, наследник, общее имущество супругов, право на наследство, корпоративные права, комплекс прав.

Abstract: The subject of this research is the court practice in regulating the transfer of shares of a limited liability corporation in case of inheritance. The author gives a thorough examination to the problems of inheritance of a portion of the shares in order to identify the cause that he sees not only in the fact that these legal relations are at the borderline of regulation of two (corporate and inheritance) legal branches, but also in the legal nature of shares in a limited liability corporation. Based on a detailed analysis of the normative base, court decisions, and theoretical research, the author questions the validity of the formed understanding of the essence of this object of civil legal relations, which does not take into account its complex nature. Based on the presumption of invisibility of rights that form the portion in the authorizes capital, the author makes a conclusion that the civil legal regime of this object should not allow transferring of portion of the rights to the inheritor or other third parties. The author also proposes to exclude the norms from the legislation that allow inheritance of a portion of the stake, since they deform the complex nature of the share and create prerequisites for acquisition of property right by the inheritor separate from corporate rights that the heir may not have due to presence of various conditions.

Keywords: Inheritance, society, stake, authorized capital, participant, inheritor, common property, heirship, corporate rights, complex of rights.

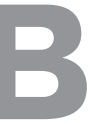

современных условиях гражданского оборота особенность гражданско-правового режима доли в уставном капитале общества с ограниченной ответственностью порождает массу пробелов в нормативном регулировании перехода права на дан- ное имущество, в том числе в порядке универсального правопреемства. Особую актуальность обозначенный вопрос приобретает применительно к условиям и порядку перехода доли в уставном капитале общества к наследнику умершего участника. Определенная 
полифония точек зрений по обозначенной теме представлена в научных публикациях, которые, преимущественно, выявляют и подтверждают примерами из деятельности судов пробелы в правовом регулировании отношений, возникающих при наследовании доли в уставном капитале общества (далее также - доля) $[1,12]$. Но в числе таких рассуждений неоднозначный подход к определению момента и условий перехода доли в уставном капитале к наследующему лицу рассматривается не в качестве консеквента какого-то заблуждения в понимании сути рассматриваемого объекта наследования, а в качестве не более чем причины для разъяснений суда высшей инстанции применительно к тому или иному вопросу наследования доли. Авторы ограничиваются положительной оценкой таких комментариев Верховного и Высшего Арбитражного Судов РФ для перспектив формирования нотариальной и судебной практики[2 ,5]. При этом представители нотариата до настоящего времени так и не утвердились в едином мнении относительно условий предоставления наследнику свидетельства на наследуемую долю, а принимаемые судами акты по делам, возникающим вследствие несовпадения интересов участников общества и унаследовавших доли лиц, все также не отличаются единообразием подходов к оценке данного условия.

В свете изложенного представляется закономерной постановка вопроса о причине описанного правового коллапса в практике наследования долей, которую, по нашему мнению, следует искать не только и не столько в нахождении рассматриваемых отношений на стыке регулирования двух подотраслей права (корпоративного и наследственного), сколько в правовой природе доли в уставном капитале общества с ограниченной ответственностью (далее также - общество, ООО). При написании настоящей статьи преследовалась цель поставить под сомнение верность сложившегося понимания сути данного объекта гражданских правоотношений, при том что проблемные вопросы наследования доли служат условным индикатором, отображающим ошибочность этого понимания.

Обратим внимание на то, что далеко не все актуальные проблемы, возникающие при наследовании доли, входят в предмет настоящей статьи, поскольку для наглядности предварительно сделанного умозаключения достаточно рассмотреть лишь один из них, а именно вопрос о наследовании доли под условием согласия остальных участников общества на переход доли к наследнику*.

* Более содержательный обзор всех аспектов наследования доли в уставном капитале ООО см. в статье Л.А. Новоселовой «Наследование доли в уставном капитале общества с ограниченной ответственностью» $[10]$.

Предлагаем обратиться к содержанию норм Гражданского кодекса РФ (далее - ГК РФ) и Федерального закона от 14.12.2011 № 14-Ф3 «Об обществах с ограниченной ответственностью» (далее - Закон об ООО), регулирующих переход доли в порядке универсального правопреемства.

Нормы раздела V части III ГК РФ «Наследственное право» содержат общие положения о наследовании имущества умершего и его переходе к другим лицам в порядке универсального правопреемства. Из общего принципа наследования, предусмотренного статьей 1176 ГК РФ, следует, что особенности наследования прав, принадлежащих умершему участнику, зависят от организационно-правовой формы юридического лица. По данной причине, помимо общей нормы названной статьи ГК РФ, при оформлении наследственных прав участника общества следует учитывать специальные нормы статьи 21 Федерального закона об ООО, регламентирующие данную процедуру применительно к этому виду хозяйственного общества.

Согласно пункту 8 статьи 21 Закона об ООО доли в уставном капитале общества переходят к наследникам граждан, являвшихся участниками общества, если иное не предусмотрено уставом общества с ограниченной ответственностью. При этом в указанной статье предусмотрена возможность ограничения перехода доли посредством указания в уставе общества согласия всех участников общества в качестве неотъемлемого условия для приобретения наследником соответствующего статуса.

Предпосылкой такого препятствия для участия наследника в корпоративных отношениях является значение его личностных и профессиональных качеств (деловая репутация, возможности и связи в сфере делового оборота и т. д.), влияющих на решение остальными участниками общества вопроса о включении потенциального партнера в свой «закрытый круг». Полагаем, что цель законодателя при формулировании положения пункта 8 статьи 21 Закона об ООО состояла в создании инструмента, позволяющего обеспечить баланс интересов участников общества и унаследовавших долю лиц, которые не имеют деловых и профессиональных преимуществ умершего участника, игравших ключевую роль в построении с ним партнерских отношений остальными участниками общества. Допускаемая законом возможность предусмотреть в уставе общества условие для перехода права на долю к наследнику демонстрирует 
DOI: $10.7256 / 1811-9018.2015 .12 .17313$

При цитировании этой статьи сноска на doi обязательна

\section{Право и политика $12(192) \cdot 2015$}

приоритет интересов участников по сохранению их состава в неизменном виде над интересом наследника по приобретению им объема прав, следующих из доли (далее также - «права из доли»).

При отсутствии в уставе специального порядка выражения согласия участников на переход доли к третьему лицу подлежат применению общие положения пункта 10 статьи 21 Закона об ООО, согласно которым согласие считается полученным при условии, что всеми участниками общества в течение тридцати дней или иного определенного уставом срока со дня получения соответствующего обращения в общество представлены составленные в письменной форме заявления о согласии на переход доли к третьему лицу (наследнику) или в течение указанного срока не представлены составленные в письменной форме заявления об отказе от дачи согласия на переход доли. Таким образом, наличие согласия участников может подтверждаться следующими способами, если альтернативный вариант выражения согласия не предусмотрен уставом общества: 1) документ, содержащий согласие на переход права на долю к наследнику, подписанный всеми участниками общества; 2) отдельные письменные заявления от каждого из участников общества; 3) протокол общего собрания участников общества, содержащий решение по соответствующему вопросу; 4) доказательства письменного обращения наследника в общество и подтверждение того, что составленные в письменной форме заявления об отказе от дачи согласия на переход доли к наследнику от участников не поступали.

Как следует из содержания пункта 2 статьи 23 Закона об ООО, в случае, если согласие участников на переход доли не получено, доля переходит к обществу в день, следующий за датой истечения срока, установленного законом или уставом для получения такого согласия. При этом у общества возникает обязанность выплатить наследнику в течение трех месяцев, если иной срок не предусмотрен уставом, действительную стоимость доли в уставном капитале общества, определенную на основании данных бухгалтерской отчетности за последний отчетный период, предшествующий дню открытия наследства, или с согласия последнего выдать ему в натуре имущество такой же стоимости.

Опираясь на приведенные статьи Закона об ООО и оценивая право членства (право на участие в управлении обществом) как право, неразрывно связанное с личностью участника, которое в силу статьи 1112 ГК РФ не входит в наследственную массу, суды зачастую делают вывод о том, что у нотариуса отсутствуют основания для предоставления наследнику свидетельства о праве, включающее наследуемую долю, при отсутствии согласия остальных участников, выраженного в любой обозначенной форме*. В таком случае в наследственную массу следует включать только «право из доли», которое корреспондирует обязанности общества выплатить наследнику стоимость доли в уставном капитале.

* См., например, Постановление ФАС Московского округа от 16.03.2010 № КГ-А40/1383-10 по делу № А40-84044/09-34-667, Постановление ФАС Западно-Сибирского округа от 17.03.2009 № Ф041465/2009(2164-А70-16) по делу № А70-5173/2008, Постановление Восьмого арбитражного апелляционного суда от 05.05.2011 по делу № А46-13898/2010, Определение Московского городского суда от 22.11.2010 по делу № 33-36239, Методические рекомендации по теме «О наследовании долей в уставном капитале обществ с ограниченной ответственностью» (утв. на заседании Координационно-методического совета нотариальных палат ЮФО, С-К ФО, ЦФО РФ $28-29.05 .2010)$.

В то же время в практике имеет место и принципиально иное применение указанных положений законодательства, когда суды оценивают предъявление наследником свидетельства о праве на наследство в качестве основания для разрешения участниками общества вопроса о переходе к наследнику доли в уставном капитале*. Иными словами, согласно этому подходу, нотариус обязан выдать наследнику свидетельство о праве на наследство, содержащее долю, поскольку именно данный документ является для остальных участников предпосылкой для постановки вопроса об участии наследника в обществе.

* См., например, Рекомендации Научноконсультативного совета по вопросам применения норм корпоративного законодательства и норм законодательства о несостоятельности (банкротстве) (утверждены Президиумом Федерального арбитражного суда Поволжского округа от 26.04.2010). Выработаны по итогам совместного заседания Научно-консультативных советов при Федеральном арбитражном суде Поволжского округа и Федеральном арбитражном суде Волго-Вятского округа, состоявшегося 25.03.2010 в г. Казани; Постановление ФАС Дальневосточного округа от 02.09.2011 № Ф033983/2011 по делу № А59-5111/2010.

Обращение к опыту нотариальной деятельности демонстрирует, что одни нотариусы отказывают в предоставлении свидетельства о праве на наследство 
DOI: $10.7256 / 1811-9018.2015 .12 .17313$

При цитировании этой статьи сноска на doi обязательна

Юридический практикум

со ссылкой на отсутствие документа, выражающего согласие всех участников общества на получение наследником соответствующего статуса; вторые - в отсутствие согласия участников - включают в состав наследуемого имущества право наследника требовать выплаты ему действительной стоимости наследуемой доли в уставном капитале; третьи - включают долю в уставном капитале в состав наследства и выдают должное свидетельство без анализа фактических отношений между наследником и участниками, оценивая данный документ как условие, позволяющее наследнику обратиться к обществу за разрешением вопроса о включении его в число участников.

В целях устранения обозначенных противоречий было принято Постановление Пленума Верховного Суда РФ от 29.05.2012 № 9 «О судебной практике по делам о наследовании» (далее - Постановление № 9), в котором указано на то, что для получения свидетельства о праве на наследство, в состав которого входит доля в уставном капитале, согласие участников соответствующего общества не требуется. В Постановлении № 9 отмечено, что выдача свидетельства является не подтверждением принадлежности наследнику всего объема корпоративных прав, а всего лишь основанием постановки вопроса о приобретении им статуса участника на рассмотрение всех имеющихся участников общества либо формой удостоверения права требовать выплаты действительной стоимости доли в случае несогласия всех или некоторых участников с вступлением наследника в общество. Тем самым Пленум Верховного Суда РФ согласился с оценкой нотариального свидетельства о праве на наследство в качестве акта, не имеющего правоподтверждающего характера и удостоверяющего лишь юридическое основание, определяющее переход к наследнику только части имущественных прав (в частности, право требовать выплату действительной стоимости унаследованной доли). Правообразующее значение для перехода к наследнику всего объема корпоративных прав, принадлежавших наследодателю при жизни, имеет выражение воли действующих участников на возникновение у наследника статуса участника.

Данное разъяснение Верховного Суда РФ дало отдельным исследователям и практикам повод для вывода о том, что при предоставлении наследнику свидетельства к нему переходят только имущественные права, но не корпоративные. Прежде чем изложить аргументированное несогласие с таким пониманием, хотим отметить, что в рамках настоящей статьи осознанно не используется оборот «право на долю», поскольку автор придерживается представленной в литературе точки зрения, согласно которой какого- либо абсолютного права на долю не существует[1]*. Считая ошибочными попытки выявить дуплицистет права применительно к доле в уставном капитале, предлагаем оценивать ее в качестве абстрактного обозначения совокупности субъективных прав, принадлежащих участнику общества с ограниченной ответственностью в силу внесения им вклада в имущество общества либо перехода к нему доли в порядке сингулярного или универсального правопреемства**.

* Обратный подход, согласно которому доля в уставном капитале общества принадлежит субъекту на абсолютном праве, представлена в статье Г. Чернышева «Оборот долей в уставном капитале»[13].

** Понимание доли в качестве способа фиксации «права на ..» и «права из» представлено, в частности, в следующих статьях: Белоотченко Е.А. «К вопросу о моменте приобретения статуса участника общества с ограниченной ответственностью в случае наследования доли в уставном капитале общества»[2]; Бобков С.А. «Уступка доли в уставном капитале общества с ограниченной ответственностью»[3].

Подтверждая статус участника в качестве субъекта «прав из доли», доля как таковая не является объектом прав и, тем более, права собственности или иного вещного права. Об обратном не могут свидетельствовать положения статьи 93 ГК РФ и статьи 21 Закона об ООО, подчеркивающие оборотоспособность доли в уставном капитале общества. Доля может переходить к третьим лицам в рамках исполнения договоров купли-продажи, дарения, залога, поскольку при этом осуществляется перемещение совокупности «прав из доли» от участника, у которого они одномоментно прекращаются, к приобретателю этих прав. Постановление Президиума Высшего Арбитражного Суда РФ (далее - ВАС РФ) от 09.02.2010 № 13944/09 по делу № А56-31225/2008 также неоправданно расценивать как допускающее применение вещных способов защиты права, в частности виндикацию, к имуществу, не являющемуся предметом материального мира, а именно к доле в уставном капитале общества с ограниченной ответственностью. В названном Постановлении отмечается возможность использования данного способа защиты вещного права применительно к доле в праве собственности на недвижимую вещь - допущение о виндикации доли в уставном капитале представляется неоправданным и искажающим подход прежней высшей судебной инстанции*. Следует отметить, что отрицание вещной 


\section{Право и политика $12(192) \cdot 2015$}

природы доли в уставном капитале общества находило неоднократное подтверждение в содержании актов ВАС РФ и судов кассационной инстанции**.

* Такая возможность допускалась, в частности, Григорьевым М. (см. «Виндицируй незримое»[7]).

** Определение ВАС РФ от 01.07.2011 № ВАС5950/11 по делу № А40-66193/10-83-605, Определение ВАС РФ от 07.09.2009 № ВАС-11093/09 по делу № А413292/08, Постановление ФАС Поволжского округа от 23.04.2012 по делу № А55-8359/2011.

Возвращаясь к вопросу о структуре и содержании прав, вытекающих из доли в уставном капитале, которую следует считать синонимичным понятием совокупности этих прав, отметим, что не только в практике по наследованию доли представлено понимание судами двух составляющих элементов данного объекта: имущественного и корпоративного. Аналогичное видение структуры доли имеет место и в научных кругах.

В частности, И. С. Шиткина, равно как и большинство иных авторов, определяет долю участника как способ удостоверения наличия совокупности имущественных и неимущественных прав участника (корпоративных прав) в отношении общества[8]. Так или иначе, но все представленные в правовой литературе определения доли используют словосочетания «совокупность прав» или «комплекс прав»[3, 6, 14]. Вне зависимости от различных аспектов этих определений, таких, например, как объем предоставляемых долей прав участника, все они выделяют в содержании «прав из доли» корпоративный или организационно-управленческий[15] элемент и имущественную составляющую, обозначая их как единую совокупность. Однако если вернуться от данного отступления обратно к вопросу о возможных судебных подходах к условиям и порядку наследования доли при том, что устав общества предусматривает необходимость согласия остальных участников на такой переход к наследнику всего объема предоставляемой долей прав, то наглядным будет условная делимость данных прав в понимании судов, в том числе Верховного Суда РФ.

Вся судебная практика, сформировавшаяся вследствие данных в Постановлении № 9 разъяснений, исходит из того, что свидетельство о праве на наследство рассматривается в качестве доказательства наследственного правопреемства доли, на основании которого наследник приобретает статус наследника имущественных прав, связанных с долей, подразумевая право требовать выплаты стоимости доли*. А вот «вторая часть» прав из доли, а именно прав корпора- тивного характера, возникает, во-первых, под условием, которым является согласие остальных участников, a, во-вторых, с определенным временным разрывом с переходом к наследнику «первой части прав», которые принято определять в качестве имущественных. При этом, имущественная составляющая прав, предоставляемых долей, неизбежно трансформируется в права на получение части чистой прибыли и ликвидационный квоты, которые могут быть реализованы участником только при наступлении ряда условий (принятие общим собранием участников решения о распределении прибыли/части прибыли и окончание процедуры ликвидации общества - применительно к праву на получение выплаты ликвидационной квоты), что позволяет нам именовать их «условными».

* Постановление ФАС Западно-Сибирского округа от 11.07.2014 №Ф04-6942/14 по делу №А4611748/2013, Постановление ФАС Дальневосточного округа от 04.02.2014 Ф03-7014/13 по делу № А591075/2011, Постановление ФАС Московского округа от 15.11.2013 №Ф05-13855/13 по делу №A40-81338/2012 // Энциклопедия судебной практики. Наследование отдельных видов имущества. Наследование прав, связанных с участием в хозяйственных товариществах и обществах, производственных кооперативах.

Предпосылки для такого разделения доли на две составляющие заложены в содержании самого Постановления № 9, где говорится о том, что отсутствие согласия остальных участников не может ограничивать наследственную правоспособность и являться препятствием для выдачи свидетельства о праве на наследство, которое, в свою очередь, не является подтверждением принадлежности наследнику всего объема прав участника. Отсюда судами делается, на первый взгляд, логичный вывод о том, что если не весь объем «прав из доли», то часть имущественных прав, как право требовать выплаты действительной стоимости доли, к наследнику переходит.

Понимание того, что права, определяющие содержание доли, делимы на две составляющие, каждая из которых (в частности, имущественная) может самостоятельно принадлежать субъекту наследования отдельно от другой (корпоративной), представлено и в судебной практике, обзор которой несколько выходит за рамки предмета, обозначенного в наименовании настоящей статьи, но соотносится с содержанием рассматриваемого вопроса.

Речь пойдет о судебной практике, формирующейся при обращении в суд «пережившего» супруга за защитой своего права на супружескую долю, 
DOI: 10.7256/1811-9018.2015.12.17313

При цитировании этой статьи сноска на doi обязательна

Юридический практикум

которой является часть доли в уставном капитале общества, приобретенной умершим участником в период нахождения в браке. В частности, обращает на себя внимание Определение Верховного Суда РФ от 14.04.2015 № 303-ЭС15-3529, которым было отказано в передаче кассационной жалобы для рассмотрения Судебной коллегией по экономическим спорам ВС РФ и тем самым признана правильность выводов судов нижестоящих инстанций, сделанных по делу № А59-4543/2013*. Предметом рассмотрения суда по указанному судебному делу являлось требование участника общества, не согласившегося с признанием отсутствующими (не возникшими) корпоративных прав (прав участника общества).

* См. Определение Верховного Суда РФ от 14.04.2015 № 303-ЭС15-3529, Постановление ФАС Дальневосточного округа от 16.02.2015 № Ф035463/2014, Постановление Пятого арбитражного апелляционного суда 14.10.2014 № А59-4543/2013, Решение Арбитражного суда Сахалинской области от 27.08.2014 по делу № А59-4543/2013.

Полагаем, что позиция Верховного Суда РФ по приведенному делу, которую хотелось бы свести к мнению одного судьи судебной коллегии, вступает в некое противоречие с ранее представленной позицией Верховного Суда РФ, изложенной применительно к вопросу о разделе в качестве общего имущества супругов доли в уставном капитале общества, - см. Определение Верховного Суда РФ от 03.06.2014 № 5-КГ4-9.

Согласно содержанию судебных актов, фабула дела заключается в следующем. На основании статьи 256 ГК РФ и статьи 34 Семейного кодекса РФ 12.03.2012 нотариусом пережившей супруге было выдано свидетельство о праве собственности на $1 / 2$ доли в общем совместном имуществе супругов, приобретенном в период брака, а именно на долю в уставном капитале общества. В этой связи супруга умершего обратилась к единственному участнику общества с заявлением о принятии ее в состав участников общества со ссылкой на факт получения ею свидетельства о праве собственности на долю и на обязанность общества в течение трех дней с момента получения уведомления обратиться в налоговый орган в связи с изменением состава участников и внести соответствующие изменения в ЕГРЮЛ. Поскольку устав общества содержал в качестве условия перехода доли к третьим лицам согласие всех участников общества, единственный участник общества, в последствии выступивший истцом по делу, отказал в переходе части доли в уставном капитале, оформленной на имя пере- жившей супруги, о чем уведомил последнюю и руководителя общества. Однако на основании поданного в налоговый орган заявления по форме с приложением упомянутого нотариального свидетельства о праве была произведена государственная регистрация изменений сведений об участниках общества (физических лицах) и в ЕГРЮЛ была внесена соответствующая запись о супруге умершего участника.

Совокупность изложенных фактов послужила основанием для обращения в суд участника, не согласившегося с приобретением супругой его прежнего партнера статуса участника общества. Применительно к рассматриваемому нами вопросу представляет интерес аргументация судов всех трех инстанций о порядке возникновения у пережившей супруги совокупности прав, следующих из доли в уставном капитале общества. Она сводится к четкому разграничению условий и момента возникновения у пережившей супруги корпоративных прав и имущественных прав, предоставляемых наследуемой долей: «пережившая супруга, получившая свидетельство о праве собственности на долю в общем имуществе супругов, включающем долю в уставном капитале общества, приобрела в отношении доли в уставном капитале лишь имущественные права, но не статус участника общества, в то время как приобретение данного статуса при наличии в уставе общества оговорки об обязательном получении согласия других участников на вступление в общество зависит от дачи ими такого согласия» (см. Постановление ФАС Дальневосточного округа от 16.02.2015 № Ф03-5463/2014).

Приведенная аргументация суда в части приобретения пережившим супругом лишь имущественных, но не корпоративных прав, предоставляемых долей, равно как и приведенные выше аналогичные суждения судов по рассмотренному вопросу об условиях наследовании доли, возвращают нас к выводу о наличии двух составляющих всего объема «прав из доли»: имущественной и корпоративной. Полагаем, что допущение судов о делимости данных слагаемых, образующих долю, и лежит в основе нестабильной судебной практики и противоречивой нотариальной деятельности, которые мы именуем «проблемами наследования доли в уставном капитале общества».

Основным выводом, который хотелось бы сделать по итогам проведенных рассуждений, является презумпция неделимости прав, которые мы отождествляем с долей в уставном капитале общества.

Доля в уставном капитале общества с ограниченной ответственностью является сложным объектом, в силу чего ей, как и всем сложным объектам, присущи признаки, вытекающие из понятия «комплекс» (от лат. complexus - связь, сочетание) - совокупность 
DOI: $10.7256 / 1811-9018.2015 .12 .17313$

При цитировании этой статьи сноска на doi обязательна

\section{Право и политика $12(192) \cdot 2015$}

элементов, составляющих одно целое[4]. А именно через определение «комплекс прав» дается определение доли в уставном капитале общества в приведенных публикациях иных авторов.

Признаками комплексного характера доли в уставном капитале общества с ограниченной ответственностью являются: множественность элементов («прав из доли»), неделимость и единство этих элементов, обособленность данной совокупности прав (доли) от иного имущества участника общества.

Множественность элементов, предполагает наличие их совокупности. Применительно к доле данный признак проявляется через принадлежность участнику общества некоторого числа прав, как то: право на участие в общем собрании участников, право на выдвижение кандидатур для избрания в органы управления, право на получение информации о деятельности общества и пр., что в совокупности определяют как права корпоративные. В числе прав, предоставляемых долей, принято выделять в отдельную группу имущественные права, связанные с распределением прибыли и получением части имущества общества при его ликвидации[8]. Ставя под сомнение допустимость определения данного элемента доли в качестве имущественных прав, полагаем, однако, что данный вопрос требует детального и самостоятельного исследования, что выходит за рамки настоящей статьи. Мы смещаем акценты с имущественной природы указанной группы прав на их комплексный характер, в котором выражается специфика доли в уставном капитале общества.

Такой признак комплекса, как обособленность доли от иного имущества участника общества, не вызывает сомнений, поскольку доля в уставном капитале общества выделяется из всей имущественной массы лица (например, из числа прочего имущества наследодателя), что позволяет ей выступать объектом сделок, то есть быть оборотоспособной.
Неделимость «прав из доли», которая игнорируется судами и остается без должного внимания со стороны исследователей*, свидетельствует о том, что все отдельные права, составляющие долю в уставном капитале, объединены и тесно связаны между собой, образуя единство и целостность. Именно на этот признак, характеризующий долю в уставном капитале, и должна быть возложена основная смысловая нагрузка определений данного объекта.

* В качестве исключения следует привести статью Л.А. Новоселовой «Оборотоспособность доли в уставном капитале общества с ограниченной ответственностью»[11], в которой отмечается, что «права, которыми наделяется каждый участник общества, характеризует и то, что они существуют в неразрывной связи друг с другом и могут быть объектом оборота только как совокупность».

С учетом изложенного считаем, что гражданско-правовой режим доли в уставном капитале не должен допускать перехода к наследникам или иным третьим лицам части «прав из доли» в силу их комплексного характера. Представляется оправданным исключение из положений ГК РФ и Закона об ООО норм, позволяющих переход доли в порядке наследования. Императивная норма о переходе доли умершего участника к обществу и обязательстве последнего выплатить действительную стоимость доли наследнику, будет исключать предпосылки для формирования «порочной» судебной практики, искажающей комплексную природу доли в уставном капитале. Более того, такое правило будет в должной мере соответствовать экономической сущности данного юридического лица, которое имеет как признак «объединение капиталов», так и признак «объединение лиц» - с присущим ему определяющим значением личностных, деловых, репутационных и прочих характеристик каждого из участников.

\section{Библиография:}

1. Бабаев А.Б., Бабкин С.А., Бевзенко Р.С., Белов В.А., Тарасенко Ю.А. Гражданское право. Актуальные проблемы теории и практики. - М., 2015.

2. Белоотченко Е.А. К вопросу о моменте приобретения статуса участника общества с ограниченной ответственностью в случае наследования доли в уставном капитале общества // Наследственное право. 2014. № 4.

3. Бобков С.А. Уступка доли в уставном капитале общества с ограниченной ответственностью // Журнал российского права. 2002. № 7.

4. Большой энциклопедический словарь. 2-е изд. - Спб. 1998.

5. Выстроп Е.И. Ростовцева Н.В. Проблемы наследования доле в уставном капитале общества с ограниченной ответственностью // Наследственное право. 2013. № 4 // СПС «Консультант Плюс».

6. Гонгало Б.М. Доля в уставном капитале общества с ограниченной ответственностью как объект гражданского оборота // Проблемы развития частного права: Сборник статей к юбилею В.С. Ема / Отв. ред.: Н.В. Козлова, Е.А. Суханов - М.: Статут, 2011.

7. Григорьев М. Виндицируй незримое // ЭЖ-Юрист. 2010. №15. СПС «Консультант Плюс». 
DOI: $10.7256 / 1811-9018.2015 .12 .17313$

При цитировании этой статьи сноска на dоі обязательна

Юридический практикум

8. Корпоративное право. Учебник / Отв. ред. И.С. Шиткина - М., 2015 // СПС «Консультант Плюс».

9. Можилян С.А. Особенности наследования доли в уставном капитале общества с ограниченной ответственностью // Наследственное право. 2014. № 1.

10. Новоселова Л.А. Наследование доли в уставном капитале общества с ограниченной ответственностью // Хозяйство и право. 2010. № 11.

11. Новоселова Л.А. Оборотоспособность доли в уставном капитале общества с ограниченной ответственностью // Статут. 2007 // СПС «Консультант Плюс».

12. Улыбин В.А. Наследование доли в уставном капитале обществ с ограниченной ответственностью // Нотариус. 2013. № 5 // СПС «Консультант Плюс».

13. Чернышев Г. Оборот долей в уставном капитале // ЭЖ-Юрист. 2005. № 38 // СПС «Консультант Плюс».

14. Шевченко С. Переход долей общества с ограниченной ответственностью // Законность. 2004. № 10;

15. Шиткина И. Доля участия в уставном капитале ООО: отчуждение, наследование, раздел // Юрист спешит на помощь. 2013. № 2 // СПС «Консультант Плюс».

\section{References (transliterated):}

1. Babaev A.B., Babkin S.A., Bevzenko R.S., Belov V.A., Tarasenko Yu.A. Grazhdanskoe pravo. Aktual'nye problemy teorii i praktiki. - M., 2015.

2. Belootchenko E.A. K voprosu o momente priobreteniya statusa uchastnika obshchestva s ogranichennoi otvetstvennost'yu v sluchae nasledovaniya doli v ustavnom kapitale obshchestva // Nasledstvennoe pravo. 2014. № 4.

3. Bobkov S.A. Ustupka doli v ustavnom kapitale obshchestva s ogranichennoi otvetstvennost'yu // Zhurnal rossiiskogo prava. 2002. № 7.

4. Vystrop E.I. Rostovtseva N.V. Problemy nasledovaniya dole v ustavnom kapitale obshchestva s ogranichennoi otvetstvennost'yu // Nasledstvennoe pravo. 2013. № 4 // SPS «Konsul’tant Plyus».

5. Gongalo B.M. Dolya v ustavnom kapitale obshchestva s ogranichennoi otvetstvennost'yu kak ob"ekt grazhdanskogo oborota // Problemy razvitiya chastnogo prava: Sbornik statei k yubileyu V.S. Ema / Otv. red.: N.V. Kozlova, E.A. Sukhanov - M.: Statut, 2011.

6. Grigor'ev M. Vinditsirui nezrimoe // EZh-Yurist. 2010. №15. SPS «Konsul’tant Plyus».

7. Mozhilyan S.A. Osobennosti nasledovaniya doli v ustavnom kapitale obshchestva s ogranichennoi otvetstvennost'yu // Nasledstvennoe pravo. 2014. № 1 .

8. Novoselova L.A. Nasledovanie doli v ustavnom kapitale obshchestva s ogranichennoi otvetstvennost'yu // Khozyaistvo i pravo. 2010. № 11 .

9. Novoselova L.A. Oborotosposobnost' doli v ustavnom kapitale obshchestva s ogranichennoi otvetstvennost'yu // Statut. 2007 // SPS «Konsul'tant Plyus».

10. Ulybin V.A. Nasledovanie doli v ustavnom kapitale obshchestv s ogranichennoi otvetstvennost'yu // Notarius. 2013 . № 5 // SPS «Konsul'tant Plyus».

11. Chernyshev G. Oborot dolei v ustavnom kapitale // EZh-Yurist. 2005. № 38 // SPS «Konsul’tant Plyus».

12. Shevchenko S. Perekhod dolei obshchestva s ogranichennoi otvetstvennost'yu // Zakonnost'. 2004. № 10;

13. Shitkina I. Dolya uchastiya v ustavnom kapitale OOO: otchuzhdenie, nasledovanie, razdel // Yurist speshit na pomoshch'. 2013. № 2 // SPS «Konsul’tant Plyus». 